\title{
Becoming a Graduate Professional Psychologist: In What Ways are Professional Competences Perceived
}

\author{
Matti Kuittinen $^{1} \&$ Hannu Räty ${ }^{1}$ \\ ${ }^{1}$ School of Educational Sciences and Psychology, University of Eastern Finland, Joensuu, Finland \\ Correspondence: Matti Kuittinen, School of Educational Sciences and Psychology, University of Eastern Finland, \\ Joensuu, Finland. Tel: 358-503-609-497. E-mail: matti.kuittinen@uef.fi
}

Received: August 11, 2014

Accepted: March 17, 2015

Online Published: May 29, 2015

doi:10.5539/ijps.v7n2p18

URL: http://dx.doi.org/10.5539/ijps.v7n2p18

\begin{abstract}
Based on the evaluations of graduate professional psychologists, this study set out to explore perceptions of university training in the development of key competencies and skills required by psychologists. The participants $(n=353)$ were a representative sample of young Finnish psychologists with professional experience of between one and six years. They were asked to rate seventeen different skills according to importance and the extent to which undergraduate training helped develop those skills. They were also asked to evaluate how their undergraduate training had fostered their skills and the work-related contexts that best nurtured their professional skills. The results show that psychology was seen as a profession requiring social interaction skills, whereas university training was seen to stress knowledge, theory and research. Respondents saw practical courses, a practicum, post-graduate education, actual work and reflecting with colleagues and with oneself as the most influential means of professional development; they saw statistical methods as being unnecessary at work. Only half of the participants could name a theory upon which their work was based. Still, graduate psychologists gave a rather positive evaluation of the correlation of their psychology training programme with the requirements of their profession.
\end{abstract}

Keywords: university training, psychologist, professional competence

\section{Introduction}

Psychology is an established profession built on a shared international and scientific basis. University psychology training aims to equip students with a solid basis for working both as practitioners in different specialisation fields and as researchers. Traditionally, there have been dilemmas between theoretically and methodologically oriented academic aspirations and the importance of developing practical skills as a requirement for the profession (Wand, 1993). While it is assumed that science-based psychology training - the so-called scientist-practitioner model-also delivers practical skills, only a couple of studies have explored whether this is actually the case. Every psychologist needs to possess key professional skills before he or she can begin independent work. But how well do psychology training institutions, where most teachers are researchers, recognise which professional skills are currently most pertinent to the practice of psychology? This study posed this question to Finnish master's level licentiates in psychology. Based on the evaluations of the graduate professional psychologists, the study set out to explore perceptions of university training in the development of key competencies and skills required by psychologists. Psychologists were also asked which aspects of their training and work had best promoted the development of their professional skills, and whether or not their work was based on a particular theory.

The European higher education curricula are currently being redesigned from the perspective of competence and skills. As a result, every educational institution in the European Union is obliged to have a clear, updated understanding of the most critical skills needed for the profession. This is vital for curriculum development, because changes in the labour market have a direct impact on the development of study programmes (Wand, 1993). Even universities are expected to meet the needs of the real working world more conclusively, rather than providing general academic education per se. Educational outcomes, such as the competency level of graduates, will more often become the target of future university assessments (Rodolfa et al., 2005). Naturally, for the majority of students, the main interest is the assumed level of employability that the degree will give (Brennan, 2010). Competent students are beneficial to the public (which they will serve), as well as to themselves, because 
they will better understand their learning goals and will be able to take more accountability for their own training (Hatcher et al., 2013).

The span of psychological practice is expanding, which further stresses the importance of work-relevant skills acquirements (Elman \& Forrest, 2007; Kaslow, 2004). Stark-Wroblewski et al. (2006, p. 276) observed, however, that undergraduate psychology students have limited information regarding the varieties of professional careers in psychology that exist, besides traditional areas such as clinical and counselling psychology. An introductory course on professional issues therefore has proved to be most valuable for psychology students' career planning (Roscoe \& Strapp, 2009). Naturally, having practical experience working as a psychologist is the most important source of information for career plans. Carless and Prodan (2003) found that students who had broad practicum training experience had much greater clarity in terms of their vocational preferences compared to those with no such practicum training. Billett (2008) argued that students expect that their professional training will consist of authentic work experiences instead of strictly theoretical training. Students also need to be adept at learning when they are at work, since the development of dispositional, procedural and conceptual capacities are required in order to achieve a good level of work performance (Billett, 2008). Students may have an unrealistic fantasy of their potential as future professionals, which will become more realistic as they witness the realities of work at an early stage (Bruss \& Kopala, 1993).

Professional university graduate programmes seek to create a close relationship between theory and practice. This can be implemented in two ways: by integrating them directly, or by creating a linear relation by first teaching the theory, which then will be followed by practical implementations. It is typical in all Finnish psychology master's programmes that theories and research methods are taught first during bachelor's degree studies; the practice-orientated studies are not taught until the master's phase. Psychology students must also understand the ethical and social challenges of their field, as well as their responsibilities to clients and to society (Karseth \& Solbrekke, 2006, p. 152). Bruss and Kopala (1993) emphasised that in addition to adding knowledge, the development of a professional identity is a necessary aspect of training, and it requires a study environment based on closeness and trust.

Psychology is taught at six universities in Finland, and is among the most popular fields of study; employment prospects are also very good for graduates. There are general national guidelines for both the curriculum and examinations, but the teaching content varies locally. The Finnish psychology curriculum is a 5.5-year generalist master's programme with a five-month practicum that prepares licentiate psychologists to work in several specialty areas with little additional training. Graduate psychologists can apply for complementary training programmes in specialty areas, such as therapy or neuropsychology. The idea behind the curriculum is that psychologists are taught generic skills that can then be applied in any domain. Students gain practical experience only in one specialty area of psychology during their five-month-long practicum. A graduate student is expected to be able to work independently after graduating, and the national licensing authority, Valvira, grants psychologists' licenses. In these respects, Finnish psychology training is rather similar to its German counterpart (Hodapp \& Langfeldt, 2006).

Despite this, there are hardly any studies on the relevance of the psychology curriculum from the viewpoint of psychologists working in real-world situations, although some studies on student curriculum preferences have been conducted. For example, Finney et al. (1989, p. 175) asked psychology students to evaluate the role of the psychology curriculum in developing their skills. The students stressed the development of written, oral and critical evaluation skills the most; they mentioned test-taking skills and managerial and organisational skills as the next three most important skills. The students felt that hands-on experience should be increased in the psychology curriculum and, interestingly, that coverage of theoretical issues should be decreased. Students felt that psychology studies had been valuable for their daily life issues, such as enhancing their social relationships at home and at work.

\subsection{Specific Skills Needed in an Expert Profession}

In seeking to identify the set of skills needed for a profession, it is important to remember the fundamental nature of all professional work. The actual work of the psychologist is that of an archetypal expert profession, in the sense that daily practice involves analysing and resolving tasks and problems that lack any stable or assured solutions since they are, by nature, intangible and ill-defined. Consequently, when meeting a new client, the first task of a psychologist is to try to specify and verbalise the core of the client's psychological problem, after which further acts can be planned. A psychologist cannot yet work on following guidelines from a scientifically tested manual that would offer solutions for solving psychological problems. This is because human behaviour is guided by complex biopsychosocial mechanisms, of which the science of psychology has as yet a rather limited 
understanding (Bandura, 2001). Orton and Weick (1990) conceived the notion of "causal indeterminacy" to refer to uncertain means-ends relations that are a central feature of the work of expert professionals in several discipline, such as teaching, consulting and psychology. To our knowledge, there are no unambiguous, scientifically confirmed interventions that can secure the expected result of resolving a client's psychological problem. Thus, the outcomes of all interventions are determined only after they have been tested in practice. In addition, various resolutions (i.e. therapy forms) can lead to the same effect (healing), resting on the client's distinctive life condition and, in particular, the quality of rapport with the psychologist. As an alternative to a small number of effective therapies, there are, to date, 166 different psychotherapies from which to select. Many new therapies, including therapies based on art, dance, music and adventure, are being developed all the time. Professional psychologists are thus forced to solve their clients' problems by testing certain interventions that they are familiar with, including the use of creativity and imagination. This aptitude can be called "flexpertise". Furthermore, the puzzles that clients bring to the table are distinctive and complex, which means that psychologists must adapt to endlessly changing situations (Alvesson, 1993).

A review of these issues suggests that it is plausible that there are no consistent and rigorous approaches for assessing the multifaceted competences and skills needed in an expert profession. For this reason, it is only possible to estimate a few easily measurable skills and areas of knowledge (Kaslow, 2004, p. 779). The use of one's "tacit knowledge", intuition and personal experience are, to a substantial degree, important in the profession (Bruss \& Kopala, 1993), yet they cannot be fully identified or verbalised, let alone quantified or instructed. Svensson (1990) interviewed psychologists and asked them how and when they used psychology theories in their actual daily work. He observed that they had clear difficulties in providing explicit illustrations. It is also worth noting that psychology, like all behavioural sciences, has been sub-divided into many sub-fields, because there are several theoretical and methodological schools of thought specialising in their particular research agendas (Wand, 1993). A psychologist working in the field therefore must choose from the different theories and approaches to guide his or her work (Karseth \& Solbrekke, 2006, p. 156). This is a major challenge, and only a few psychologists lean on a specific theory. Moreover, half of the graduate students surveyed by Perl and Kahn (1983, p. 143) stated that their preferred theoretical method was eclectic, borrowing from several theories. Pelling (2007, p. 219) confirmed this finding after studying counselling psychology in Australia. A similar trend was also evident in our study sample.

While scientific theories and formal knowledge only offer a small part of the professional knowledge that psychologists need to help solve their clients' problems, they offer a solid basis for professional development during one's career. Still, uniqueness, volatility, complication and ambiguity are always present in actual work practice. Although the immediate connection between work practice and scientific knowledge is open to criticism, science-based academic education provides power and prestige to a profession, and every profession has a desire to sustain its independence, reputation and jurisdiction (Wand, 1993). For this reason, both professionals and academic faculty members want to sustain academic values, and they need research institutions for their professional education (Karseth \& Solbrekke, 2006, p. 163).

In the most favourable cases, the skills required in a profession like psychology evolve from the outset of one's career, which makes efforts to outline professional skills even more intricate. The majority of professional psychologists obtain new qualifications after graduation; in countries such as Finland this is even expected, since formal psychology education provides no specialisation. Informal work-based learning promotes intentional or unintentional scholarship. Intentional learning endeavours, such as acquiring a new therapy technique, are more straightforward to investigate, illustrate and distinguish from one another. Unintentional learning, on the other hand, can happen under several conditions, such as during an exchange of ideas on problematic cases between co-workers, or from receiving feedback from co-workers (Berg \& Chyung, 2008). Skills can degrade over time if psychologists do not keep up with the newest developments in their field, and regularly work to update their knowledge in response to these developments. Professional skills are specific to certain areas of specialisation, such as neuropsychology; highly developed expertise thus can only be achieved in a limited area of knowledge (Barnett et al., 2007).

It is noteworthy to include the ongoing discussion on the origin of skills. The question is whether professional skills can be taught to everyone, or if they are innate and can be further nurtured during the training phase to reach an expert level. On the basis of the above discussion, it is interesting to delve into the development of professional skills as described by graduate psychologists themselves. 


\subsection{Definitions of Psychology Skills}

Several different endeavours around the world have aimed to coherently outline the skills required by the psychology profession. The American Psychological Association (APA) Competencies Conference constructed the first consistent competence description for psychology by 130 attending psychologists (Kaslow et al., 2004). At this conference, it was determined that the following areas relating to values, mindsets and knowledge were central to professional psychologists working in health and human services. These are: (a) research methods and scientific bases of psychology; (b) ethical, legal and public policy issues; (c) professional development issues; (d) psychological assessment; (e) intervention; (f) individual and cultural diversity; (g) consultation and interdisciplinary relationships and (h) supervision.

Rodolfa et al. (2005) further developed this categorisation with an exploratory cube model consisting of the following components: functional and foundational competencies added to the stage of professional maturity, and ranging from the undergraduate level to the doctoral stage. "Foundational competencies" refer to what psychologists do in reality. They are labelled: (a) scientific knowledge/methods, (b) reflective practice/self-assessment, (c) relationships, (d) individual/cultural diversity, (e) ethical/legal standards/policy and (f) interdisciplinary systems. These aptitudes are learnt during graduate studies. "Functional competency" portrays the spheres of a psychologist's professional functioning. These competences are composed of: (a) research/evaluation, (b) intervention, (c) supervision/teaching, (d) assessment/diagnosis/case conceptualisation, (e) consultation and (f) management/administration. Further, Rodolfa et al. (2005) offered a comprehensive characterisation of each competency domain.

The Finnish Psychological Association has proposed the key elements of the work of a psychologist as follows: intervention, training, publishing, psychological assessment, work development and administration (Näätänen et al., 2008). EuroPsy is a European standard of professional training and psychology education. A EuroPsy certificate is granted to a candidate who can master these competences: definition of the objective, communication, psychological assessment, development, intervention, self-assessment and activities that promote competence growth (http://www.efpa.eu). The representatives of the Australian educational psychology institutions, together with members of the Australian Psychological Society (APS), grouped the competences under the following headings: professional, legal and ethical approach; measuring and solving problems; discipline knowledge; influence and change research; framing, professional and community relationship; and service implementation and communication (Garton, 2006). In Canada, qualified psychologists are required to be equipped in the following psychology competency areas: (a) research, (b) intervention and consultation, (c) assessment and evaluation, (d) ethics and standards and (e) interpersonal relations (Rodolfa et al., 2005).

Putting together these categorisations, the most generic skills are consultation, psychological assessment, intervention, professional growth, scientific fundamentals of psychology, legal and ethical issues and interdisciplinary interactions. These classifications are, however, limited, since they are relative hypothetical portrayals of skills that are obviously arduous to make operational for appraisal purposes. Our study set out to build a simple instrument to evaluate basic skills that are learnt in (and demanded from) professional psychology work practice. We chose the self-assessment technique to assess these skills (Kaslow, 2004). First, we explored numerous surveys validated by our universities in their alumni feedback research for appraising general academic skills taught at university. Second, we meticulously chose the key skills that are most relevant in professional psychology when assessed against the major psychology competency descriptions. Following this, the selected statements were sent for examination to every psychology department in Finland, as well as to ten senior professional psychologists; very few (and minor) changes were suggested.

This study concentrates on the following research problems, as perceived by graduate psychologists:

(1) How does the university training of psychologists respond to the skills needed at work?

1) In which areas is university education seen to provide good work-related skills?

2) In which areas is education seen to fail to provide sufficient skills for psychology work?

(2) How do psychologists perceive the role of theoretical training, work, continuing education and reflection in enhancing their professional skills? Is their work based on a particular theory?

(3) Which undergraduate courses and aspects of training are seen to promote best the development of your professional skills? 


\subsection{Participants}

In the autumn of 2008, an e-mail was sent to every Finnish psychologist who graduated between 2002 and 2007, totalling 1,193 people. The e-mail asked the recipients to fill in a questionnaire via a given web address. A reminder was posted after two weeks. The response rate was 30 percent $(\mathrm{N}=353)$. A great majority of the participants were female (91 percent), which is in accordance with the general gender distribution of psychologists. The mean age of the participants was 33 years $(\mathrm{SD}=4.7) ; 88$ percent were under 36 years of age. The number of respondents who graduated in each of the six years varied between 46 and 74 . The vast majority of participants ( 90 percent) worked in the public sector, and nine out of ten had obtained their positions within three months of graduation.

\subsection{Questionnaire}

The questionnaire instructions read, "How important are the following knowledge areas and skills to your current job? Also assess how well your university training developed these skills". The participants were presented with seventeen skill-related statements (see Figure 1) and were asked to evaluate them twice-first, in terms of how important they were to the profession, and second, the extent to which their undergraduate training helped develop them. A five-point Likert-type scale was used, which consisted of the following options: (1) "very poorly", (2) "poorly", (3) "satisfactorily", (4) "very well" and (5) "excellently".

In addition, the psychologists were asked to respond to five statements relating to the meaning and importance of university training, actual work experience, further education, self-reflection and reflection with colleagues on their own professional skills development. To ensure full coverage of the survey, an additional three open questions were presented: (i) whether their work was based on a particular theory, and if so, to name it; (ii) which undergraduate courses and aspects of their work had been most beneficial for their professional skills development; and (iii) they were further asked about the occasions during their career during which they had learnt the best new skills, although this data was not analysed here. Only one respondent was unable to identify any specific, professionally beneficial undergraduate course. These items therefore produced rich data.

\section{Data Analysis}

The quantitative ratings and written statements were analysed separately. The analyses were conducted using IBM Statistical Package for the Social Sciences (SPSS) statistics 21. Differences between the psychologists' conceptions of how university training developed certain skills and the precise meaning of these skills at work were analysed with the Wilcoxon matched pairs signed-ranks test. The relation between university training and work-related learning was analysed using non-parametric (Spearman's rho) correlations. The connection between theoretical work orientation and work experience was analysed with the $\chi^{2}$ test, in which the effect size was measured with Cramer's V test. Due to the low number of male psychologists and the large variety of specialisation areas, the comparisons were only performed against the above-mentioned variables.

The written statements were analysed following Braun and Clarke's (2006) six phases of conducting thematic analyses. First, the themes were inductively discovered and elaborated with a "bottom-up" or grounded theory analytic process by systematically grouping together statements based on their similar semantic meanings. This was continued until distinctive, coherent and consistent themes were identified. We then went back to the raw data and grouped all responses into these themes. Themes are patterned responses or meanings which both minimally organise and best describe the dataset in its richness. This allows theoretical interpretations of its various aspects by relying both on their content and their frequency of occurrence (Braun \& Clarke, 2006, pp. 79-82). The analysis sought to understand the multiple meanings that psychologists gave to their study experiences and professional development in a transparent and credible way.

\section{Results}

\subsection{Correlation of University Training with Professional Needs}

Figure 1 demonstrates the striking differences between the skills needed at work and those learnt in university. Statistical difference comparisons indicated that for all skills except information acquiring skills, the difference was statistically significant (Wilcoxon matched pairs signed-ranks test $\mathrm{p}<.05$ ). University training was seen mostly to have promoted scientific skills, such as research, information acquisition and the understanding of theories in psychology. Knowledge about assessment methods and their scientific basis, as well as analytical and systematic thinking skills, were seen as having been well developed during the graduate training. These skills were also evaluated as having been valuable in the psychology work context. Respondents found that managerial skills had not been taught, nor were they needed by psychologists. 


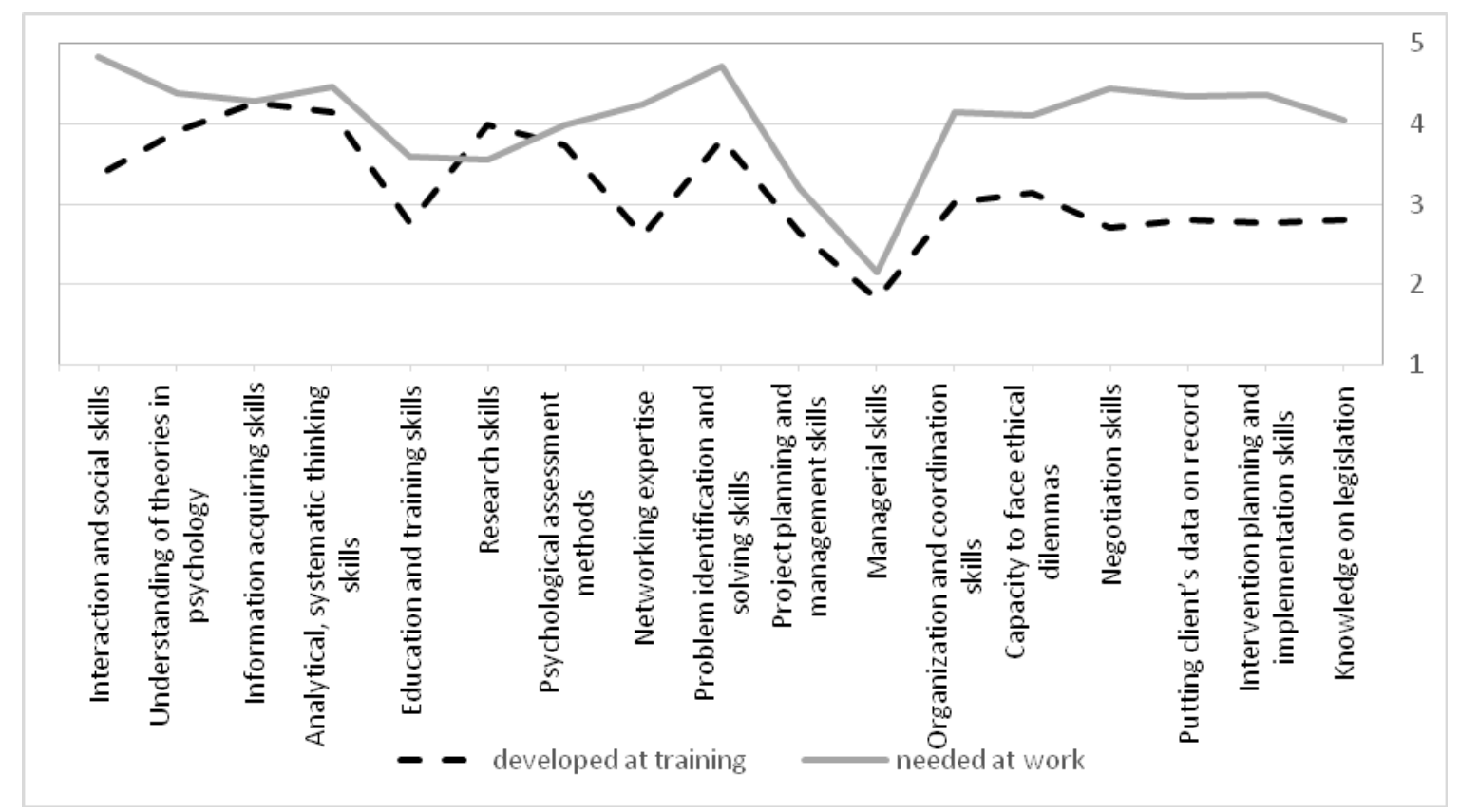

Figure 1. Psychologists' mean ratings of skills learnt at university vs. those needed at work

On the subject of other skills, several striking differences emerged, in particular, in the area of social skills. According to psychologists, their work was most of all about social interaction with clients, where negotiation, problem identification and solving, intervention planning and implementation skills and networking expertise were most needed. Knowledge about legislation, how to put clients' data on record and education and training skills were also seen as being very valuable in the work practice of psychologists. Organisation and coordination skills, along with the capacity to act when faced with ethical dilemmas, were also required at work. In all of these key skills, university training was seen as failing to react appropriately to the changing needs of the profession; therefore, the respondents deemed the correlation of the curriculum with real-world work tasks to be very low.

\subsection{Important Learning Contexts for Professional Skills}

We now review the learning contexts for professional skills. Table 1 indicates that practical work tasks and the work context were evaluated as being the most effective for professional skills growth. The importance of colleagues is striking, since reflection and dialogue with them were seen as vital for learning professional skills. Self-reflection and in-service training were the next two most influential means of skills development. The role of graduate training was seen as moderately positive but was less important when compared with other measured work-based learning context variables (Wilcoxon match pairs signed-ranks test $\mathrm{p}<0.001$ ). These variables correlated slightly negatively, emphasising their divergence.

Table 1. The means and inter-correlations of the statements on professional development

\begin{tabular}{llllll}
\hline Statement of professional skills & \multicolumn{5}{c}{$\begin{array}{l}\text { Non-parametric/Spearman's rho } \\
\text { /Correlations }\end{array}$} \\
\hline & $\mathrm{M}(\mathrm{SD})$ & 1. & 2. & 3. & 4. \\
1. Master's degree provided good professional skills & $3.43(.95)$ & & & & \\
2. Postgraduate and in-service training have been useful & $4.42(.78)$ & .07 & & & \\
3. Only practical work has developed my professional skills & $4.68(.56)$ & $-.21^{*}$ & .07 & & \\
4. Reflection with colleagues has developed my professional skills & $4.69(.52)$ & .02 & .07 & $.14^{*}$ & \\
5. Self-reflection has developed my professional skills & $4.46(.58)$ & -.02 & .10 & $.14^{*}$ & $.29^{*}$ \\
\hline
\end{tabular}

Note. ${ }^{*} \mathrm{p}<.01$ (two-tailed) 


\subsection{The Role of Psychological Theories at Work}

We now examine the responses to the open-ended questions. First, the role of theory was elucidated by asking the respondents whether their work was based on a particular theory or theories, and if so to identify theories on which they drew during the course of their work. Responses were placed into two groups according to work experience. The results are shown in Table 2. As in previous research, half of the respondents could name a theory they followed in their work, and those who did mentioned eclectic uses of theories or referred mostly to cognitive theory. No consistent trend emerged in terms of the frequency of theory use. There were differences only within groups with one, four and six years of work experience $\left(\chi^{2}[5]=13,538, p=.02, \mathrm{~V}=.196\right)$.

Table 2. Responses to the question of whether work was based on any specific theory in accordance with actual work experience

\begin{tabular}{llll}
\hline Work experience in years & No theories mentioned n (\%) & Theory or theories mentioned n (\%) & Total \\
\hline 1 & $38(61 \%)^{* *}$ & $24(39 \%)^{* *}$ & 62 \\
2 & $27(48 \%)$ & $29(52 \%)$ & 56 \\
3 & $32(43 \%)$ & $42(57 \%)$ & 74 \\
4 & $22(34 \%)^{* *}$ & $43(66 \%)^{* *}$ & 65 \\
5 & $20(44 \%)$ & $26(56 \%)$ & 46 \\
6 & $30(60 \%)^{* *}$ & $20(40 \%)^{* *}$ & 50 \\
Total & $\mathbf{1 6 9 ( 4 8 \% )}$ & $\mathbf{1 8 4}(\mathbf{5 2 \%})$ & $\mathbf{3 5 3}$ \\
\hline
\end{tabular}

Note. ${ }^{* *} \mathrm{p}<.05$ difference between "No theories mentioned" and "Theory mentioned" groups

\subsection{The Most Influential Undergraduate Courses for Learning Professional Expertise}

The following thematic analysis is based on respondents' written comments on their undergraduate learning experiences. Most comments included content on numerous themes; thus, they were rigorously classified under each corresponding theme, for a total of 844 classified items.

Table 3. Responses to the question on the most influential undergraduate courses for learning professional expertise

\begin{tabular}{|c|c|c|}
\hline Theme & Content Areas & Frequencies \\
\hline Professional practices & $\begin{array}{l}\text { Professional and clinical practice, } \\
\text { professional } \\
\text { competence education and advanced professional courses }\end{array}$ & $20 \%(\mathrm{n}=170)$ \\
\hline Psychological assessment & $\begin{array}{l}\text { Psychological tests, research methods in psychology, } \\
\text { psychological assessment and writing statement, as well as } \\
\text { courses on interview skills }\end{array}$ & $18 \%(\mathrm{n}=150)$ \\
\hline Psychology theories & $\begin{array}{l}\text { Theoretical courses on developmental, neuro- and clinical } \\
\text { psychology and other theories of psychology }\end{array}$ & $16 \%(\mathrm{n}=132)$ \\
\hline Learning practical work & $\begin{array}{l}\text { Studies on the necessary skills relating to the practical } \\
\text { work of the psychologist, the application of theoretical } \\
\text { knowledge and skills relating to interacting with clients }\end{array}$ & $13 \%(n=107)$ \\
\hline Practicum & $\begin{array}{l}\text { Preparatory studies and orientation training for the } \\
\text { practicum, pre-practicum, practicum }\end{array}$ & $8 \%(n=72)$ \\
\hline Therapeutic skills & $\begin{array}{l}\text { Learning a general or specific therapy like cognitive } \\
\text { psychotherapy and obtaining basic therapeutic skills }\end{array}$ & $7.0 \%(\mathrm{n}=59)$ \\
\hline $\begin{array}{l}\text { Interaction } \\
\text { counselling skills }\end{array}$ & $\begin{array}{l}\text { Interpersonal, guidance and counselling skills; group } \\
\text { dynamics; encountering a patient, client or family; } \\
\text { presentation skills; communication training and } \\
\text { negotiation skills }\end{array}$ & $5 \%(\mathrm{n}=39)$ \\
\hline
\end{tabular}




\begin{tabular}{lll}
$\begin{array}{l}\text { Criticism and } \\
\text { improvement proposals }\end{array}$ & Critical comments on teaching and development proposals & $5 \%(n=44)$ \\
$\begin{array}{l}\text { Research method skills } \\
\text { Minors and elective } \\
\text { studies }\end{array}$ & Scientific research methodology and master's thesis & $3 \%(n=30)$ \\
Ethics and law & Mentions of minors and elective studies & $3 \%(n=28)$ \\
\hline
\end{tabular}

Most respondents emphasised studies that directly enhanced their professional capability but with slightly different names. Respondents referred to professional practice courses, professional work courses, clinical courses, clinical professional practice studies and vocational studies. Real or imaginary patients were encountered in the best courses, and practical skills, such as the ability to work with clients, were learnt efficiently. The second theme, psychological assessment courses, entailed skills on the usage and effectiveness of tests (62), assessment methods (31), interview skills (30) and writing statements (27) by practicing them with the help of a teacher with hands-on experience. Courses that gave a theoretical basis to work were mentioned 95 times. The most frequently mentioned (and only specified) courses were clinical psychology (32), neuropsychology (19) and developmental psychology (17); otherwise, the respondents spoke of basic or theoretical courses on a general level. Several courses were mentioned only once. Learning practical work referred to learning experiences that familiarised one with concrete work content, applying theoretical knowledge to practice, acquiring the skills and working methods of working life (37) and helping and interacting with clients (29). Teaching methods, such as case studies and demonstrations (24) and using discussion and tutorials (17), were most beneficial in this respect.

On the subject of therapy skills, there were general comments about therapy aptitudes (34) but more specific remarks about psychotherapy (25), including cognitive and family-related therapy, which respondents saw as intervention tools. Respondents did not clarify why these skills were perceived to be important. Relating to the theme of interaction and counselling, there were mentions of interpersonal negotiation skills (17), group work dynamics (11), patients' family relations (4), counselling (4) and presentation skills (3). Criticism and improvement proposals were aimed mainly at one issue area - there was a strong need to add more practical training to the curriculum (29) as well as adding a second practicum (6). The remainder of the comments (9) were mentions about teaching, such as increasing interaction. Surprisingly, there were only a few viewpoints on research methods, the second main target of the curriculum. In this context, the master's thesis (12) and research method skills (18) were mentioned as being valuable learning experiences. Minors and elective studies were mentioned (28) because they provided a counterweight to the psychology perspective and because they were practical. Ten respondents mentioned courses relating to either professional ethics or legislation.

When asked for specifics, the practicum appeared to be a major phase both during studies and during respondents' careers, as the respondents (144) found that they had most efficiently learnt professional work skills during the practicum. They learnt a significant amount during the practicum, and after receiving timely guidance and feedback, they had the experience of actual psychology work and the opportunity to apply theory to practice.

\section{Conclusion and Discussion}

This article contributes to the methodological and conceptual development of measuring professional skills among psychologists. Empirical research has been either minimal or completely lacking in this area. As there are no developed, standardised methods, this exploratory study and its preliminary results are an important step in contributing to the empirical research in this area.

Our results showed that the graduate programme was thought to be somewhat successful only in relation to certain skills: in particular, theoretical and research know-how. This has also been demonstrated in data by Peluso et al. (2010). Psychology students and teachers clearly differ in their expectations of courses. Teachers emphasise the intellectual nature of a course, whereas students place more importance on the practical aspects of the course's content. Roberts (1981) has stressed that psychology students seem to enter college with a positive expectation of practical knowledge. In this study, these items were also cited as being the most useful.

In addition, theoretical education was only seen as being useful when it was applicable in practice. Karseth and Solbrekke (2006, p. 156) observed that Norwegian psychology students felt that their studies were a kind of dualistic education, with these dyads representing two different forms of logic. Theory represents formal, science-based qualifications, whereas practice represents the practical wisdom of the psychology profession. 
Although, according to Karseth and Solbrekke (2006), the Norwegian students preferred practice to theory and actually saw them as two separate worlds, they appreciated their scholarly training - as did their Finnish colleagues in the current study. The students in the present study, however, remained very ambivalent, and questioned whether the theories they had learnt were applicable in practice. The functioning of the scientist-practitioner curriculum model is therefore laden with tension and is ambivalent.

When asked about theories they applied in their work, half of the participants could name one, a result which is consistent with previous research (Pelling, 2007, p. 219; Perl \& Kahn, 1983). This finding is understandable in light of the concept of "loose-coupling" (Orton \& Weick, 1990) and the specific ontological nature of psychology as a fragmented human science (Bandura, 2001) in which the scientific laws found in the natural sciences are lacking. Gelso (2006) has reminded us that scientific theories should conceivably maintain the role of indirect relevance to professional work. Theoretical understanding provides a strong foundation for the success of rapid learning during the practicum, and at work thereafter. Statistical methods are highly valued by academics, but only six psychologists (mostly researchers) saw them as being useful to their profession. This verdict is rather shocking and ought not to be disregarded or defensively overlooked.

When it comes to the core skills of the psychology profession—social interaction and communication skills- the study found that university training is seen to develop these skills far less than is required by real-world workplaces. As a result, there is a huge gap between professionally important skills and skills generated through university teaching. Whether or not teaching these professionally important skills is practicable is another matter. We can pose several questions: what is the role of basic training in the development of these abilities, and what abilities are expected to evolve with work experience (e.g., with in-service training) (Scheeres et al., 2010)? It is questionable whether it is even possible or reasonable to teach social skills, and whether a high level of social skills should be a major criteria for student recruitment in the first place. Graduate psychologists, however, most strongly indicated the role of the practicum in providing authentic work experience with clients, and where dialogue with colleagues and self-reflection best enhanced their professional development.

According to our findings, the workplace was seen as the most influential learning context for the development of psychologists' professional skills. Undergraduate training can therefore be interpreted as a foundation for learning these skills in practice. Based on the tacit knowledge of university trainers, there is the hypothesis that after five years of working as professional psychologists, "graduates will be practicing from their experience more than from any training that we provided" Doll (2007, p. 514). At work, however, the individual's viewpoint is not sufficient, since learning is collective (Marsick, 2009). Our results give strength to the view that workplace learning should be made visible and should be considered to be valuable as undergraduate training. Workplace learning actions should thus be targeted, designed and instructed, and learning should be assessed and shared (Billet, 2002). The data from this study suggests that during the practicum and upon starting a new job, the arranged supervision is valued (and even highly celebrated) and is seen as an abundant learning phase. Learning later becomes more informal and more serendipitous, and it happens in the process of solving complicated client cases and in similar situations. We were unable to assess how many of the respondents were open to continuous learning at work; further study is therefore needed to improve awareness of possibilities and prerequisites of work-related learning. This would support the continuing professional development of psychologists in the workplace, and would help with the curriculum development of university degree programmes.

Learning in a work context was appraised as being important in the early years of one's career, although this was far from straightforward. In our previous analysis (Kuittinen et al., 2013), we noted that recent psychology graduates also appraised their mastery of professional skills at a high level, which is both arguable and surprising. In that study we contended that perhaps these graduates did not yet know that in the future, their skill mastery level would be even higher than the perceived peak they were experiencing at the time (Baron et al., 1984). Kruger and Dunning (1999) maintained that the novices lacked the metacognitive skills necessary for truthful self-assessment; they therefore experienced hindrances as they received feedback and learnt about the good work of others, even when others observed them. The enhancement of metacognitive skills and self-assessment should therefore be included in undergraduate training programmes, since they are learnable aptitudes (Eva, Cunnington, Reiter, Keane, \& Norman, 2004). A learning portfolio offers students good tools for this, since it forces students to reflect on their learning and who they are as people and as future professionals (Larkin, Pines, \& Bechtel, 2002).

The psychologists surveyed evaluated the significance of university education in a positive way, although they felt that it did not cultivate all the key skills they needed. The status of having a university degree may have supported their positive attitude. They evidently accepted the fact that professional "flexpertise" can only be 
learned at work, where client cases are both multifaceted and ill-defined. Their engagement in work-based learning was very strong, since they had internalised that learning, and professional developmental needs were a fundamental aspect of work (Billett, 2001). More than ever before, there is a growing need for governments, employers and workers themselves to update their skills throughout working life. The aim of this kind of informal, work-based learning may be to resist redundancy, make effective work transitions as occupational requirements change, contribute to continuity and development in the workplace and contribute to the economic prosperity of communities (Billett, 2008).

Based on these findings, university training is about building a bridge between theory and practice. This bridge remained unfinished for half of the participants, since they could not make any linkages between their work and the available theories. The underlying principle behind valuable learning experiences was the practical application of theoretical knowledge. Developing teaching methods that simulate authentic situations encountered at work could thus offer solutions to combining theories with the skills needed in the profession (Billet \& Choy, 2012, p. 269). According to Hays and Vincent (2004), problem-based learning is also an effective method in psychology, since it promotes several skills, such as critical thinking, oral presentation ability and knowledge acquisition. Theory and practice can be further integrated by using several practice over a five-month period instead of one practicum. For example, the bachelor's programme could combine visits to specialised areas in the field with small-scale learning or ancillary tasks. This would create a valuable opportunity for highly valued experiential learning in a real-world work context at the very beginning of one's career.

This study has several limitations. First, presumably, only active and motivated psychologists responded, which might have distorted the findings in a positive direction. Second, all the typical limitations of a survey apply to this research, too. Third, the lack of any validated instruments forced us to build a new questionnaire. Although it was carefully tailored to our target group, it needs further testing. Nevertheless, the high scores on most of the skills studied clearly indicate that the selected items were very relevant for the psychology profession as well as in the curriculum content. The use of open-ended questions enhanced ecological validity (i.e. they approximated the real world), thus allowing respondents to express their authentic and main undergraduate and work learning experiences. Naturally, this is not a catch-all method, nor is it assumed as such. An open-ended question was used to solicit information about the use of specific theories at work in order to allow more detailed responses. When presented with a list of theories, anyone can choose something. This does not rule out the implicit use of psychological theories, which would be an intriguing topic for further research. This would be similar to the practicum, which was seen as playing a vital role in learning (Chandler \& Williamson, 2013). The results in this study are based on cross-sectional data on young Finnish psychologists, and longitudinal studies are needed for the further development of professional skills in several specialty areas later in one's career. Fundamentally, this requires the development of sensitive methods for assessing the learning of professional skills that are prerequisites for intangible and ill-defined tasks. In our data, problem identification was assessed as the most crucial skill in the profession. Replicating the methods from other fields (such as medicine) thus overlooks the ontological difference between these disciplines, as the target of medicine is to cure physical, tangible diseases and injuries with standard interventions that often save human lives.

It would also be noteworthy to study the obstacles or impediments in the work of psychologists that have an impact on workplace learning. The manner in which individuals reason, absorb and learn can be conceptualised though the use of the term "bounded agency" (Billet \& Choy, 2012, p. 270). Accordingly, individuals operate in a zone between their capabilities and their exercise of agency. Agency is, in turn, constrained by boundaries, the violation of which leads to sanctions. This places more experienced co-workers in a position whereby they are able to facilitate or inhibit learning processes.

Training institutions could employ this kind of method when seeking the opinions of alumni professionals who can credibly evaluate their undergraduate learning from a professional perspective. According to these results, undergraduate training in Finland provides a firm basis for learning professional skills in a concrete psychology work context. A study on Canadian students produced similar findings (Peluso et al., 2010), and it is a comforting message to participating scientific institutions.

\section{References}

Alvesson, M. (1993). Organizations as rhetoric: Knowledge-intensive firms and the struggle with ambiguity. Journal of Management Studies, 30(6), 997-1015. http://dx.doi.org/10.1111/j.1467-6486.1993.tb00476.x

Bandura, A. (2001). The changing face of psychology at the dawning of a globalization era. Canadian Psychology/Psychologie Canadienne, 42(1), 12-24. http://dx.doi.org/10.1037/h0086876 
Barnett, J. E., Doll, B., Younggren, J. N., \& Rubin, N. J. (2007). Clinical competence for practicing psychologists: Clearly a work in progress. Professional Psychology: Research and Practice, 38(5), 510-514. http://dx.doi.org/10.1037/0735-7028.38.5.510

Baron, A., Sekel, A. C., \& Stott, F. W. (1984). Early career issues for counseling center psychologists: The first six years. The Counseling Psychologist, 12(1), 121-125. http://dx.doi.org/10.1177/0011000084121011

Berg, S. A., \& Chyung, S. Y. (2008). Factors that influence informal learning in the workplace. Journal of Workplace Learning, 20(4), 229-244. http://dx.doi.org/10.1108/13665620810871097

Billett, S., \& Choy, S. (2012). Learning through work: Emerging perspectives and new challenges. Journal of Workplace Learning, 25(4), 264-276. http://dx.doi.org/10.1108/13665621311316447

Billett, S. (2001). Learning through work: Workplace affordances and individual engagement. Journal of Workplace Learning, 13(5), 209-214. http://dx.doi.org/10.1108/EUM0000000005548

Billett, S. (2002). Critiquing workplace learning discourses: Participation and continuity at work. Studies in the Education of Adults, 34(1), 56-67.

Billett, S. (2008). Emerging perspectives on workplace learning. In S. Billett, C. Harteis, \& A. Eteläpelto (Eds.), Emerging perspectives of workplace learning (pp. 1-15). Rotterdam: SensePublishers.

Braun, V., \& Clarke, V. (2006). Using thematic analysis in psychology. Qualitative Research in Psychology, 3(2), 77-101. http://dx.doi.org/10.1191/1478088706qp063oa

Brennan, J. L. (2010). Employability of university graduates and graduate outcomes. In P. Peterson, E. Baker, \& B. McGaw (Eds.), International encyclopedia of education (3rd ed., pp. 354-359). Oxford, UK: Elsevier. http://dx.doi.org/10.1016/B978-0-08-044894-7.00826-5

Bruss, K. V., \& Kopala, M. (1993). Graduate school training in psychology: Its impact upon the development of professional identity. Psychotherapy, 30(4), 685-691. http://dx.doi.org/10.1037/0033-3204.30.4.685

Carless, S. A., \& Prodan, O. (2003). The impact of practicum training on career and job search attitudes of postgraduate psychology students. Australian Journal of Psychology, 55(2), 89-94. http://dx.doi.org/ 10.1080/00049530412331312944

Chandler, K. M. M., \& Williamson, D. L. (2013). Explicating practicum program theory: A case example in human ecology. Journal of Experiential Education, 36(3), 188-202. http://dx.doi.org/10.1177/ 1053825913489101

Doll, B. (2007). How do we know when we have found competence? Professional Psychology: Research and Practice, 38(5), 514-515.

Dunning, D., Johnson, K., Ehrlinger, J., \& Kruger, J. (2003). Why people fail to recognize their own incompetence. Current Directions in Psychological Science, 12(3), 83-87. http://dx.doi.org/10.1111/ $1467-8721.01235$

Elman, N., \& Forrest, L. (2007). From trainee impairment to professional competence problems: Seeking new terminology that facilitates effective action. Professional Psychology: Research and Practice, 38(5), 501-509. http://dx.doi.org/10.1037/0735-7028.38.5.501

Eva, K. W., Cunnington, J. P. W., Reiter, H. I., Keane, D. R., \& Norman, G. R. (2004). How can I know what I don't know? Poor self-assessment in a well-defined domain. Advances in Health Sciences Education, 9(3), 211-224. http://dx.doi.org/10.1023/B:AHSE.0000038209.65714.d4

Finney, P., Snell Jr., W., \& Sebby, R. (1989). Assessment of academic, personal, and career development of alumni from Southeast Missouri State University. Teaching of Psychology, 16(4), 173-177. http://dx.doi.org/10.1207/s15328023top1604_1

Garton, A. F. (2006). Competence: Defining, assessing and maintaining competence to practice. In S. Morrissey, \& P. Reddy (Eds.), Ethics \& professional practice for psychologists (pp. 63-73). South Melbourne, Australia: Thomson Social Science Press.

Gelso, C. J. (2006). On the making of a scientist-practitioner: A theory of research training in professional psychology. Training and Education in Professional Psychology, S(1), 3-16. http://dx.doi.org/10.1037/ 1931-3918.S.1.3 
Hatcher, R. L., Fouad, N. A., Campbell, L. F., McCutcheon, S. R., Grus, C. L., \& Leahy, K. L. (2013). Competency-based education for professional psychology: Moving from concept to practice. Training and Education in Professional Psychology, 7(4), 225-234. http://dx.doi.org/10.1037/a0033765

Hays, J. R., \& Vincent, J. P. (2004), Students' evaluation of problem-based learning in graduate psychology courses. Teaching of Psychology, 31(2), 124-126.

Hodapp, V., \& Langfeldt, H. P. (2006). Learning and teaching psychology as a major subject in Germany. International Journal of Psychology, 41(1), 24-28. http://dx.doi.org/10.1080/00207590444000429

Karseth, B., \& Solbrekke, T. D. (2006). Characteristics of graduate professional education: Expectations and experiences in psychology and law. London Review of Education, 4(2), 149-167. http://dx.doi.org/10.1080/ 14748460600855252

Kaslow, N. J. (2004). Competencies in professional psychology. American Psychologist, 59, 774-781. http://dx.doi.org/10.1037/0003-066X.59.8.774

Kaslow, N. J. et al. (2004). Competencies conference: Future directions in education and credentialing in professional psychology. Journal of Clinical Psychology, 80, 699-712. http://dx.doi.org/10.1037/ 0003-066X.59.8.774

Kruger, J., \& Dunning, D. (1999). Unskilled and unaware of it: How difficulties in recognizing one's own incompetence lead to inflated self-assessments. Journal of Personality and Social Psychology, 77(6), 1121-1134. http://dx.doi.org/10.1037/0022-3514.77.6.1121

Kuittinen, M., Meriläinen, M., \& Räty, H. (2013). Professional competences of young psychologists: The dimensions of self-rated competence domains and their variation in the early years of the psychologist's career. European Journal of Psychology of Education, 29(1), 63-80. http://dx.doi.org/10.1007/ s10212-013-0187-0

Larkin, J. E., Pines, H. A., \& Bechtel, K. M. (2002). Facilitating students' career development in psychology courses: A portfolio project. Teaching of Psychology, 29(3), 207-210. http://dx.doi.org/10.1207/ S15328023TOP2903_05

Marsick, V. J. (2009). Toward a unifying framework to support informal learning theory, research and practice. Journal of Workplace Learning, 21(4), 265-275. http://dx.doi.org/10.1108/13665620910954184

Näätänen, P., Blåfield, J., Hakkarainen, S., Hallantie, M., Hynninen, T., Koskinen, S., \& Väänänen, T. (2008). Psykologityön palvelutoimintojen luokitusopas [The classification guide of the psychologist's work]. Helsinki: Stakes.

Orton, J. D., \& Weick, K. E. (1990). Loosely coupled systems: A reconceptualization. Academy of Management Review, 15(2), 203-223. http://dx.doi.org/10.2307/258154

Pelling, N. (2007). Advertised Australian counselling psychologists: A descriptive survey of their practice details and self-perceived competence in six counselling psychology practice areas. Counselling Psychology Quarterly, 20(3), 213-227. http://dx.doi.org/10.1080/09515070701475784

Peluso, D. L., Carleton, R. N., \& Asmundson, G. J. G. (2010). Clinical psychology graduate students' perceptions of their scientific and practical training: A Canadian perspective. Canadian Psychology/Psychologie Canadienne, 51(2), 133-139. http://dx.doi.org/10.1037/a0018236

Perl, K., \& Kahn, M. W. (1983). Psychology graduate students' attitudes toward research: A national survey. Teaching of Psychology, 10(3), 139-143. http://dx.doi.org/10.1207/s15328023top1003_4

Roberts, A. E. (1981). Making a "successful" course: Faculty and student perspectives. Teaching of Psychology, 8(4), 234-237. http://dx.doi.org/10.1207/s15328023top0804_13

Roberts, M. C., Borden, K. A., Christiansen, M. D., \& Lopez, S. J. (2005). Fostering a culture shift: Assessment of competence in the education and careers of professional psychologists. Professional Psychology: Research and Practice, 36(4), 355-361. http://dx.doi.org/10.1037/0735-7028.36.4.355

Rodolfa, E., Bent, R., Eisman, E., Nelson, P., Rehm, L., \& Ritchie, P. (2005). A cube model for competency development: Implications for psychology educators and regulators. Professional Psychology: Research and Practice, 36(4), 347-354. http://dx.doi.org/10.1037/0735-7028.36.4.347 
Roscoe, L. J., \& Strapp, C. M. (2009). Increasing psychology students' satisfaction with preparedness through a professional issues course. Teaching of Psychology, 36(1), 18-23. http://dx.doi.org/10.1080/ 00986280802529426

Rubin, N. J. (2007). En route to competence: Still on the road but making progress. Professional Psychology: Research and Practice, 38(5), 516-517.

Rubin, N. J. et al. (2007). The competency movement within psychology: An historical perspective. Professional Psychology: Research and Practice, 38(5), 452-462. http://dx.doi.org/10.1037/0735-7028.38.5.452

Scheeres, H., Solomon, N., Boud, D., \& Rooney, D. (2010). When is it OK to learn at work? The learning work of organisational practices. Journal of Workplace Learning, 22(1/2), 13-26. http://dx.doi.org/10.1108/ 13665621011012825

Stark-Wroblewski, K., Wiggins, T. L., \& Ryan, J. J. (2006). Assessing student interest and familiarity with professional psychology specialty areas. Journal of Instructional Psychology, 33(4), 273-277.

Svensson, L. (1990). Knowledge as a professional resource: Case studies of architects and psychologists at work. In R. Torstendahl, \& M. Burrage (Eds.), The formation of professions: Knowledge, state, and strategy (pp. 51-70). London: Sage Publications.

Wand, B. (1993). The unity of the discipline: A challenge for the profession. Canadian Psychology, 34, $124-131$. http://dx.doi.org/10.1037/h0078760

Ward, M. L., Gruppen, L., \& Regehr, G. (2002). Measuring self-assessment: Current state of the art. Advances in Health Sciences Education, 7(1), 63-80. http://dx.doi.org/10.1023/A:1014585522084

Younggren, J. N. (2007). Competence as a process of self-appraisal. Professional Psychology: Research and Practice, 38(5), 515-516.

\section{Copyrights}

Copyright for this article is retained by the author(s), with first publication rights granted to the journal.

This is an open-access article distributed under the terms and conditions of the Creative Commons Attribution license (http://creativecommons.org/licenses/by/3.0/). 